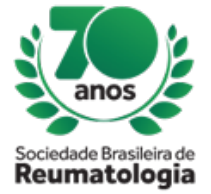

\title{
NUTRITIONAL STATUS RELATED TO SELENIUM IN GIRLS WITH JUVENILE SYSTEMIC LUPUS ERYTHEMATOSUS
}

Rogerio do Prado (UNIFESP, SÃO PAULO, SP, Brasil), Jade Dib Fernandez (UNIFESP, SAO PAULO, SP, Brasil), Fabiola I. S. Souza (Unifesp, sao paulo, SP, Brasil), Roseli O. S. Sarni (unifesp, sao paulo, SP, Brasil), Claudio A Len (UNIFESP, SAO PAULO, SP, Brasil), Maria Teresa S L R A Terreri (Unifesp, Sao Paulo, SP, Brasil)

\section{BACKGROUND}

Recent advances in the diagnosis and treatment of juvenile Systemic Lupus Erythematosus (jSLE) have modified the morbidity and mortality profile of patients. Disease-related lethality declined; however, complications such as osteoporosis, dyslipidemia and cardiovascular diseases have increased. Among the various components of the antioxidant defense that participate in cellular metabolism, selenium is the one that exerts important functions in the body, such as protection against chronic diseases, including cardiovascular diseases. Selenium acts through selenoproteins, such as glutathione peroxidase (GPx) for the evaluation of oxidative stress. The objective of this study was to evaluate the nutritional status related to selenium in girls with jSLE.

\section{MATERIALS AND METHODS}

A cross-sectional and controlled study included 31 adolescent girls with a diagnosis of jSLE. We excluded patients on methylprednisolone or cyclophosphamide, and patients with acute infection at the time of evaluation. We collected: anthropometric data, disease activity, biomarkers related to lipid metabolism, HOMA-IR (insulin resistance), plasma selenium and GPx. Statistical analysis: Chi-square, Fisher Exact and T Student tests $(p<0.05)$.

\section{RESULTS}

Selenium concentrations below the reference value of 46 microgram/L were observed in 15 (48.3\%) jSLE patients, with no difference in relation to controls. The mean concentrations of GPx were significantly lower in the jSLE group $(p<0,05)$. The weight-to-height ratio, insulin, HOMA-IR were higher in the patients compared to controls. Mean concentrations of triglycerides and total cholesterol and fractions did not differ between groups.

\section{CONCLUSION}

The low concentrations of GPx observed in patients compared to controls, although with no difference in selenium levels, point to the risk of lipid peroxidation and atherosclerosis in jSLE. 